ИЗВЕСТИЯ АКАДЕМИИ НАУК ЭСТОНСКОИ ССР. ФИЗНКА МАТЕМАТИКА

PROCEEDINGS OF THE ACADEMY OF SCIENCES OF THE ESTONIAN SSR.

PHYSICS * MATHEMATICS

$1986,35,3$

\title{
ИЗМЕРЕНИЕ ПРОФИЛЕИ ВОЗБУЖДЕНИЯ РЕЗОНАНСНОГО КОМБИНАЦИОННОГО РАССЕЯНИЯ СВЕТА В РЕЖИМЕ ШАГОВОГО ДВОЙНОГО СКАНИРОВАНИЯ
}

\author{
(Представил К. К. Ребане)
}

Развитие новых методов оптической лазерной спектроскопии привело к значительному углублению наших знаний о возбужденном состоянии вещества. Этой цели - получению детальной информации об электронноколебательных возбуждениях конденсированного вещества - служит новый вид оптических спектров, получивших название профилей возбуждения (ПВ) линий резонансного комбинационного рассеяния (PКР) $\left[{ }^{1,2}\right]$.

ПВ выражают зависимость сечения комбинационного рассеяния с рождением (уничтожением) кванта данного собственного колебания от частоты возбуждения при сканировании последней через электронноколебательную полосу поглощения вещества. В известном смысле измерение ПВ аналогично измерению спектров возбуждения люминесценции: в обоих спектрах требуется получить зависимость интегральной интенсивности сигнала от частоты возбуждения, приведенной к постоянному числу падающих фотонов. Однако имеются существенные отличия, делающие измерение ПВ самостоятельной и нетривиальной экспериментальной задачей.

Во-первых, вид спектра обычной люминесценции очень слабо зависит от возбуждения $\omega_{л}$ в пределах одной полосы поглощения, поэтому для измерения спектра возбуждения люминесценции достаточно сканировать только частоту (⿻). Спектр РКР смещается вслед за частотой возбуждения, поэтому для измерения ПВ РКР необходимо при каждой частоте возбуждения $\omega_{л}$ прописывать участок спектра РКР, содержащий данную линию, т. е. необходимо двойное сканирование.

Во-вторых, сечение PKР на много порядков меньше сечения обычной люминесценции. Поэтому измерение сигнала РКР предъявляет очень высокие требования к уровню паразитного рассеянного света на месте измерения линии и чувствительности всей системы электронной регист. рации.

Предлагаемая ниже система шагового двойного сканирования является первой в мировой практике автоматизированной системой для из. мерения ПВ РКР. Имеющиеся в литературе экспериментальные данные о ПВ получены «по точкам», что, как правило, приводит к потере единого масштаба измеряемого сигнала и ставит перед экспериментато. рами проблему т. н. внутреннего репера или иных эталонов сравнения

Комплекс аппаратуры, использованной для измерения ПВ РКР в автоматическом режиме шагового двойного сканирования, схематически показан на рис. 1. Вся система управляется блоком числового программного управления (БУ), который включает микропроцессор INTEL 
$8085 \mathrm{~A}$ (близкий аталог К580ИК80, 256 байт оперативной памяти. 2 к байт постоянной памяти и интерфейсы).

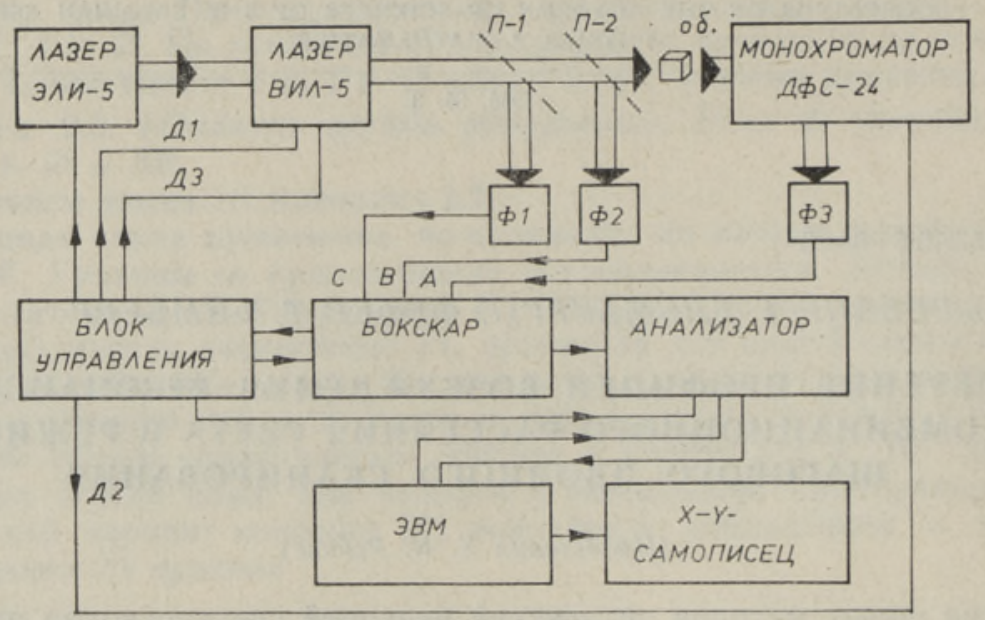

Рис. 1. Блок-схема автоматизированной установки для измерения профилей возбуждения резонансного комбинационного рассеяния света: П1, П2 - светоделительные пластины, Об - исследуемый объект, Ф1 - фотодиод с формирователем синхроимпульсов, Ф2 - детектор реперного сигнала, Ф3 - ФЭУ.

Для возбуждения объекта исследования мы использовали лазер на растворах красителей ВИЛ-5, выпускаемый Институтом физики и Тартуским филиалом СКБ АН ЭССР, накачиваемый электроразрядным эксимерным лазером ЭЛИ-5 [3]. Лазер ЭЛИ-5 генерирует импульсы длительностью $10-20$ нс с энергией 50-100 мДж (в зависимости от состава рабочей смеси) при частоте повторения до 100 Гц. Лазер ВИЛ-5 со сменными красителями генерирует импульсы почти той же длительности в широкой спектральной области с энергией до 5 мДж в импульсе и спектральной шириной линии не более $0,15 \AA$ без эталона и не более $0,04 \AA$ с эталоном Фабри-Перо. В этот лазер была дополнительно вмонтирована спектральная развязка между осциллятором и усилителем, подавляюшая широкополосный фон более чем в $10^{3}$ раз до интенсивностей $10^{-7}-10^{-8}$ от интенсивности лазерной линии [ [ ${ }^{4}$. Уменьшение фона позволило перестраивать частоту возбуждения без дополнительной системы отчистки лазерной линии.

Рассеянный от объекта исследования сигнал собирается фокусирующей системой и поступает на двойной решеточный монохроматор ДФС-24, на выходе которого он регистрируется скоростным фотоумножителем EMI 9810A (с постоянной времени 3 нс и усилением до нескольких десятков милливольт на каждый падающий фотон) и подается на вход $A$ двухканального бокскар-интегратора ВCI 176 . На вход $B$ бокскар-интегратора подается реперный сигнал от детектора лазерного возбуждения на основе ФЭК-22, необходимый для нормировки на интенсивность возбуждения. Запуск ВСI 176 синхронизован с импульсами возбуждения по каналу $C$ от детектора на основе ФЭК-22 (Ф1 на рис. 1). Синхроимпульс открывает с заданной временной задержкой временные окна в каналах $A$ и $B$, в которых осуществляется накопление заданного числа $k$ импульсов полезного сигнала и сигнала возбуждения соответственно. Суммированные за $k$ импульсов сигналы после аналого-цифрового преобразования (АЦП), выполненного дополнительным АЦП с разрядностью. 10 бит, запоминаются в двух последующих каналах многоканального анализатора NTA-1024. Сопряжение.БУ и ВСI осуществляет 
следующие функции: в БУ передается сигнал о выполнении $k$ импульсов. после чего в ВСІ блокируется синхросигнал.

Временные окна ВСI 176 могут варьироваться в соответствии с задачей эксперимента в пределах $10^{-9}-10^{-3}$ с и их правильный выбор позволяет существенно уменьшить вклад люминесценции и темновых шумов в регистрируемый сигнал РКР по сравнению с системами, использующими стащионарное возбуждение.

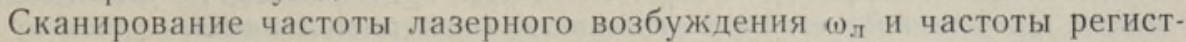
ращии $\omega_{м}$ монохроматором осуществляется шаговыми двигателями ШДР711, управляемыми БУ по каналам Д,$Д_{2}$ и Д тель поворачивает эталон Фабри-Перо в резонаторе лазера. Управление шаговыми двигателями проводится с помощью интерфейсов ШД ДШРЧ-ЭОООЗ ТО, выпускаемых Тартуским филиалом СКБ АН ЭССР.

Спектральная чувствительность системы регистрации РКР, включающей фокусирующие линзы, монохроматор и ФЭУ, была промерена и затабулирована с помощью эталонной светоизмерительной лампы с ленточным телом накала. Спектральная чувствительность датчика ФЭК-22 промерена на установке «Спектр» $\left[{ }^{5}\right]$ *.

Цикл измерения ПВ данной линии в спектре РКР начинается с установки исходных частот лазерного возбуждения $\omega_{\pi^{\prime}}{ }^{0}$, монохроматора $\omega_{м}{ }^{0}$ и режима работы бокскар-интегратора - выбора временного окна и числа $k$ накапливаемых импульсов. Затем выбираются параметры сканирования, в число которых входят: шаг сканирования $\Delta \omega_{\mathrm{m}}$ и число точек $n$ сканирования монохроматора через линию PKР, шаг сканирования $\Delta \omega_{л}$ и число точек $m$ в спектре ПВ (в каждой точке $m$ измеряются линии РКР), а также частота следования лазерных импульсов $v$. После ввода исходных данных и параметров сканирования в БУ последний обеспечивает по специальной программе управление всем циклом измерений. В результате одного цикла двойного шагового сканирования оказывается записанным $m$ спектров РКР в заданной области от $\omega_{\mathrm{M}}$ до $\omega_{\mathrm{M}}+n \Delta \omega_{\mathrm{M}}$ при частотах возбуждения, отличающихся на величину $\Delta \omega_{л}$.

Дальнейшая обработка спектра, проводимая на мини-ЭВМ ЕMG $666 \mathrm{~B}$, включает в себя поправку на спектральную чувствительность в каналах $A$ и $B$, нормировку линий PKР на интенсивность падающего лазерного излучения, а также вычисление интегральной интенсивности (площади) под линией PKР, которое производится после вычитания усредненного фона. Результирующие спектры выводятся на $X$ - $Y$-самописец и запоминаются на магнитной ленте.

Полученные после такой обработки данные представляют зависимость интегральной интенсивности линии РКР от частоты возбуждения, приведенную к постоянному числу падающих фотонов. Эта зависимость правильно передает ПВ данной линии РКР при условии не очень сильного поглощения света в образце, т. е. при условиях, когда можно не учитывать изменение глубины проникновения возбуждающего света и реабсорбцию света рассеяния.

Ниже приведены результаты измерения на описанной выше установке ПВ для линии колебания (1) $=283 \mathrm{~cm}^{-1}$ в спектре PKP стандартного кристалла $\mathrm{CaCO}_{3}$ при комнатной температуре. Были приняты следующие значения параметров: $\omega_{\text {л }}^{0}=21487 \mathrm{~cm}^{-1}, \Delta \omega_{л}=25 \mathrm{~cm}^{-1}, \quad m=20 ; \omega_{\mathrm{M}}^{0}=21154 \mathrm{~cm}^{-1} ; \Delta \omega_{\mathrm{M}}=1 \mathrm{~cm}^{-1}$, $n=100, k=32, v=30$ Гц. Использовалась генерация красителя кумарин 47 при энергии накачки в импульсе 40 мДж. Серия линий $\omega_{1}$ в зависи-

* Авторы выражают благодарность Т. Тынниссону и Р. Графу за любезное представление возможности воспользоваться установкой «Спектр» и оказанную при этом помощь. 
мости от частоты возбуждения на рис. 2, a представляет собой данные канала $A$ после внесения поправок. Область сканирования $\omega_{л} 21500-$ 22000 находится далеко от края собетвенного поглощения кальцита, поэтому сечение рассеяния должно иметь обычную лля нерезонансного рассеяния гладкую частотную зависимость $S \sim \omega_{\pi} \omega^{3}$. На рис. $2, \sigma$ точками показаны нормированные площади под линиями РКР, приведенными на рис. $2, a$, которые хорошо удовлетворяют теоретической зависимости. Среднеквадратичное отклонение экспериментальных точек от теоретической кривой составило $3 \%$, что не превышает ошибки измерения по стандартной схеме («по точкам») с использованием эталонов сравнения $\left[{ }^{6}\right]$. Время записи и обработки данных в режиме двойного шагового сканирования составило около 2 ч, тогда как аналогичные измерения «по точкам» с учетом необходимой перефокусировки требуют десятков часов рабочего времени.
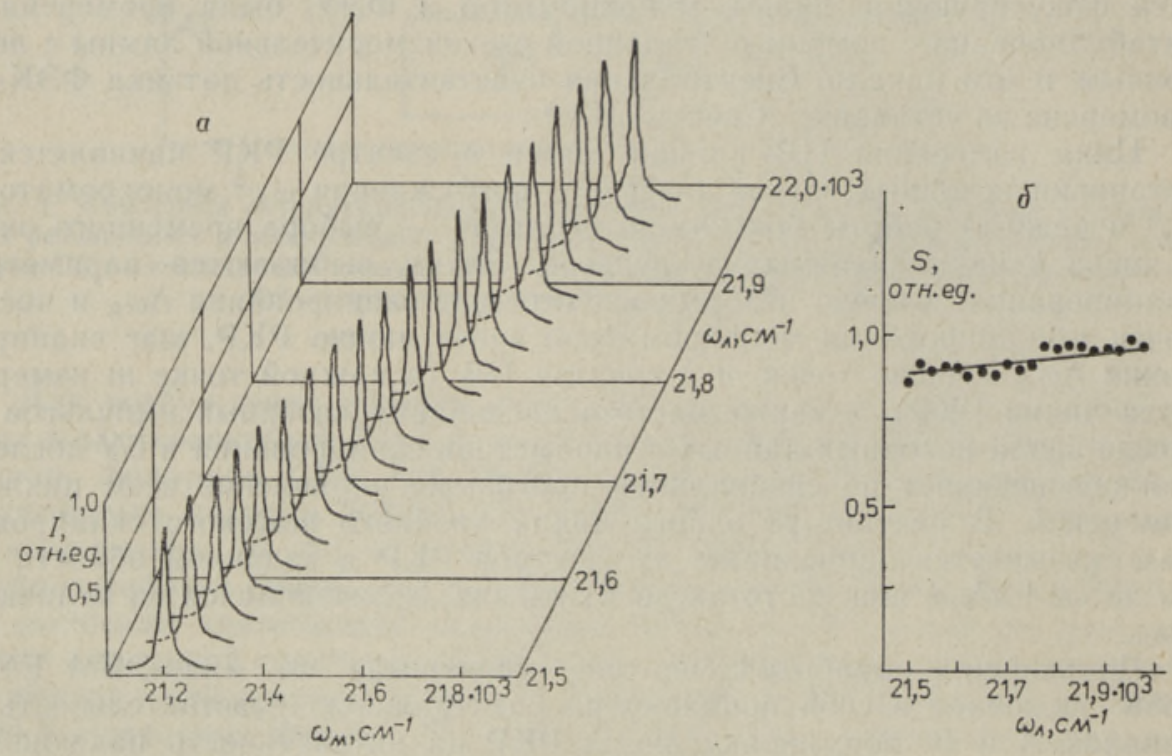

Рис. 2. Спектр профилей возбуждения комбинационного рассеяния на полносимметричном колебании $\omega_{1}\left(283 \mathrm{~cm}^{-1}\right)$ кристалла $\mathrm{CaCO}_{3}$ при $300 \mathrm{~K}: a-$ зависимости линий комбинационного рассеяния от частоты возбуждения $\omega_{л}, \sigma-$ профиль возбуждения комбинационного рассеяния: точками показаны площади под линиями комбинационного рассеяния, приведенными в $a$, сплошная линия - вычисленное изменение профиля возбуждения нерезонансного комбинацнонного рассеяния.

Описанная здесь установка шагового двойного сканирования позволяет полностью автоматизировать измерение такой сложной спектральной характеристики как профиль возбуждения спектра РКР. При этом удается добиться высокой точности получаемых результатов без использования дополнительного эталона и одновременно в несколько раз сократить время эксперимента, что важно в условиях ограниченного ресурса стабильности современных лазеров на красителях. Параметры имеющейся в нашем распоряжении спектральной аппаратуры позволяют регистрировать сигнал с интенсивностью не менее $10^{-8}$ от интенсивности возбуждения. Однако с помощью этой схемы можно регистрировать более слабые световые потоки при условии использования более совершенной спектральной аппаратуры.

В заключение авторы считают своим долгом выразить благодарность Е. Берику за помощь в наладке системы лазерного возбуждения, 
1. Hizhnyakov, V., Tehver, I. Phys. Status solidi (b), 21, 755 (1967).

2. Siebrand, W., Zgierski, M. Z. In: Excited States (ed. E. C. Lim). New York-London, et al., Academic Press, 1979, 2-136.

3. Берик E. Б., Михкельсо В. Т. Сб. тр. конф. «Лазерное оптическое и спектральное приборостроение». Минск, 1983, 185-197.

4. Берик Е. Б. Тр. ИФ АН ЭССР. Лазерная техника, № 56, 107-112 (1984).

5. Тынниссон Т. А., Вейсманн У. К., Граф Р. Э., Кольк Р. О., Мяртин Л. О., Тоотс К. О. Сб. тр. 5 Всесоюзной научно-технической конференции «Фотометрия и ее метрологическое обеспечение». М., 1984, 173.

6. Хаав А. А., Халлер К. Э., Техвер И. Ю., Ребане Л. А. Физ. твердого тела, 26, № 11, $3280-3289$ (1984).

Институт химической и биологической физики Академии наук Эстонской ССР

Поступила в редакцию

11/XII 1985

\author{
Ljubov REBANE, G. BLUMBERG, E. FEFER, T. FIMBERG
}

\title{
VALGUSE RESONANTSE KOMBINATSIOONHAJUMISE ERGASTUSPROFIILIDE SPEKTRITE MOOTTMINE KAHEKORDSE SAMMSKANEERIMISE REZIIMIS
}

On esitatud täielikult automatiseeritud süsteem valguse resonantse kombinatsioonhajumise ergastusprofiilide spektrite mõõtmiseks kahekordse sammskaneerimise režiimis impulsslaserergastusega.

Süsteem võimaldab suure aja- ja laseriressursside säästuga mõōta valguse kombinatsioonhajumise spektreid signaali suhtelise intensiivsusega kuni $10^{-8}$ pealelangevast ¡a nende ergastusprofiile suhtelise täpsusega môni protsent.

\section{Lyubov REBANE, G. BLUMBERG, E. FEFER, T. FIMBERG \\ RESONANT RAMAN EXCITATION PROFILE MEASUREMENTS BY STEPPED DOUBLE SCANNING}

A fully automatized system is described for measuring resonant Raman excitation profiles by stepped double scanning under pulsed laser excitation.

The system makes it possible to measure Raman spectra with the relative intensities of scattered and incident light up to $10^{-8}$ and the Raman excitation profiles with the relative accuracy of a few per cent. The system uses time and laser resources very economically. 